\title{
Os restos na história: percepções sobre resíduos
}

\section{Waste over history: perceptions about residues}

Abstract This article describes how $M$ an, over history, felt about the residues produced by human activity. The text is divided into three parts: In the first part it tells the story of the black plague pandemic during the XIV century, showing how this disease was associated with the residues produced by the human body. In the second part it explains how the first notions of waste were, and still are, related to dirt, diseaseand death. Finally, in the third part, it describes the first measures of hygiene in the Renaissance and refers to the first public health actions at the beginning of the XX century, starting to combat the agents of infectious diseases and their vectors.

Key words Public health, Health and disease, Environment, Residues, Waste
Resumo 0 artigo busca, em diferentes períodos da história, as percepções sobre os resíduos resultantes da atividadehumana. Está dividido em três partes: 1) narra o episódio da pesten egra do século XIV, mostrando como ela foi associada aos resíduosproduzidos pelo corpo humano; 2) explicita como as prenoções sobre resíduos, ainda hoje, remetem à sujeira, à doença eà morte; 3) descreve as medidas de higiene, a partir do renascimento ea saúde pública no início do século XX, que começa combatendo os agentes microbianos das doenças infecciosas e os seus vetores.

Palavras-chave Saúde pública, Saúde e doença, Ambiente, Resíduos, Lixo 
Introdução

0 lixo é definido pelo dicionário Aurélio ${ }^{1}$ como aquilo que se varre da casa, do jardim, da rua e se joga fora; entulho. Tudo o que não presta e se joga fora. Sujidade, sujeira, imundície. Coisa ou coisas inúteis, velhas, sem valor. Resíduos que resultam de atividades domésticas, comerciais, industriaise hospitalares. Também classifica e defini o lixo, segundo o risco que causa à população, como atômico, espacial, radioativo e especial - os resíduos re sultantes de atividades industriais poluentes.

No presente artigo, o lixo é descrito como o resíduo desprezado e temido pelo homem. Ele representa o resto da atividade humana ou a sobra indesejada de um processo de produção, que tanto podeestar associada à eliminação demicroorganismos patogênicos veiculados pelos fluidos e dejetos corporais como ao descarte de resíduos atômicos, radioativos e industriais poluentes.

$\mathrm{Na}$ Idade M édia, a maioria dos restos resultantes da atividade do homem estava diretamente relacionada aos resíduos produzidos pelo seu corpo - fezes, urina, secreções em geral e o próprio corpo humano em decomposição. Também havia os restos provenientes da alimentação carcaças de animais, cascas de frutas e hortaliças.

Os restos começaram a causar medo no homem, a partir do momento em que foram sendo associados ao seu sofrimento físico e psíquico. Esse sofrimento ficou bem marcado na ocasião do surto manifestado pelas epidemias e pandemias de algumas doenças na Idade M édia, mais precisamente pela peste negra no continente europeu durante o século XIV.

Neste sentido, vamos observando, no decorrer da história, que o homem no seu processo de elaboração do conhecimento vai associando segundo sua sensibilidade e sensações, os fatos vivenciados. E que, através da percepção, ele vai ordenando e dando forma a esses fatos, os quais, por sua vez, vão sendo exteriorizados em diversas e diferentes formas de expressões. Entretanto, cabe acrescentar que a cultura constitui fator essencial no processo de construção do saber e, portanto, na representação do imaginário social. Assim, o estudo busca, em diferentes períodos da história, as percepções do homem sobre os resíduos resultantes das suas atividades.
Osresíduos como veículos deimpurezas eenfermidades

Com a intenção de mostrar no decurso da história dos restos, o significado da doença no corpo, tomamos a peste como referência na construção do conhecimento sobre os resíduos. A relação entre corpo, doença eresto vai originar as representações sociais sobre enfermidade e resíduo, uma vez que foi se tornando difícil falar de uma sem tocar no outro.

Nestesentido, descrever os sintomase as conseqüências da peste, no medievo, épensar na produção de resíduos ou na transfiguração do corpo humano em restos repugnantes. A representação dos resíduos foi sendo construída pelo imaginário social, segundo as tragédias causadas pelas epidemias e pandemias de "pestes".

A elaboração da associação entre peste e produção de resíduos foi fundamentada nas obras de Ursino ${ }^{2}$ e de Dessennius ${ }^{3}$, descritas no século XVI e encontradas na seção de obras raras da Biblioteca Geral da Universidade de Coimbra em Portugal.

Na Idade M édia, as palavras "praga", "peste" ou "pestilência" significavam a aparição de uma enfermidade epidêmica, que produzia um alto índice de mortalidade. $\mathrm{N}$ em sempre o termo se referia à peste negra ou bubônica, já que outras epidemias como gripe, tifo, cólera evaríola, contagiosas e letais, também estavam presentes. No entanto, os sintomas da peste bubônica foram descritos em detalhes. Houve, assim, pestes ou pragas famigeradas que chegaram a ser denominadas com o nome do lugar onde começaram ou onde foram mais graves. A peste do século XIV, chamada de "morte negra ou peste negra" foi a mais célebre pela sua mortandade 2 .

As "pestes" causavam temor e, no período medievo, muitas vezes foram interpretadas como "castigo divino", pelos pecados que o homem havia cometido. Além dessa crença, os homens também acreditavam que as enfermidades poderiam ser transmitidas pelo ar corrompido teoria dos miasmas - e já percebiam que o contágio da doença se dava de pessoa a pessoa. Fato que começou a gerar medo na aproximação com o outro, o que poderia propiciar o contato com as secreções eliminadas pelo doente durante 0 processo da enfermidade, tais como o sangue e 0 pus provenientes dos bubões, no caso da peste bubônica. 0 terror causado pela doença está visível na seguinte descrição do estado do enfer$\mathrm{mo}^{2}:[\ldots]$ alguns cuspiam sangue, outros tinham no corpo, manchas roxas escuras e destas ninguém 
escapava. Os doentes tinham apostemas ou estrumas nas ínguas ou debaixo das axilas, e destes alguns escapavam, e temos de dizer que estes enfermos eram muito contagiosos e que quase todos os quecuidavam dos enfermos, morriam, assim como os sacerdotes que recolhiam as confissões. O Papa ordenou que, quando morresse um pestilento, todas as pessoas presentes ou próximas, dissessem: que D eus te bendiga $[\ldots]^{2}$.

As epidemias, como punição dos deuses, pareciam constituir uma associação importante, já presente na antiguidade. 0 texto da "peste", em O vídio descrito por Diniz ação entre "pestes" e castigo divino: o flagelo terrível queatacou o povo teria sido provocado pela ira de Juno junto à terra. Além da doença como castigo divino, mas atribuída às condições climáticas, encontramos os dizeres de O vídio, sugerindo que a peste brotou com ímpeto, quando [...] 0 céu cobriu a terra com uma escuridão profunda eencheu essas trevas com um calor sufocante. 0 cálido Austro soprou um vento mortal [...] era evidente que a peçonha se espalhava pelas fontes epel os lagos, equemilhares de serpentes, errando pelos campos incultos, contaminaram os rios com o seu veneno[... $]^{4}$.

0 pensamento médico fundamentado na teoria das influências astrais ressaltava o ar como o meio de transmissão das doenças. Eram o ar envenenado, os miasmas e as névoas pesadas e pegajosas, provocando todos os tipos de agentes naturais e imaginários, desde águas estagnadas dos lagos e rios, até a conjunção negativa dos planetas que disseminavam a doença e a morte entre os homens. Assim, segundo a concepção dos miasmas, o ambiente corrompido das habitações e os hábitos das pessoas eram também associados à propagação da peste.

0 ambiente interno das moradias era o mesmo - tanto os lares mais humildes como os castelos de pedra dos senhores feudais possuíam um único cômodo grande. Situação que agravava os problemas relativos à saúde de seus habitantes. 0 principal agente insalubre era a coabitação com os animais de criação; outro problema dizia respeito à falta de ventilação. A maioria das casas tinha um piso de terra batida, sendo aquecidas por uma lareira central. As camas geralmente eram envolvidas por cortinados, que proporcionavam maior privacidade. N essas camas, largas e compridas, dormiam até oito pessoas. As condições internas das habitações, como a umidade, a fumaça, a ausência de privacidadee a conseqüente promiscuidade, eram agentes eficazes na transmissão de doen ças. N este ambien- te corrompido, se um membro da família contraísse alguma doença, era tarefa muito difícil evitar o contágio².

As cidades, no medievo, eram densamente povoadas. Os resíduos - fezes, urina e águas fétidas- eram lançados pelas janelas. As roupas eram lavadas raramente e, como conseqüência, elas ficavam infestadas de pulgas, percevejos, piolhos e traças. Quem mais corria risco eram os recémnascidos, já que as mulheres, ao dar a luz, costumavam forrar as camas com lençóis usados. Entre um quarto e um terço das crianças morriam antes de completar um ano e muitas outras antes dos dez anos. De cada dois nascimentos bemsucedidos, somente um chegava à idade adulta. As casas eram ninhos de ratos que disputavam os restos de comida com os animais de criação ${ }^{3}$.

O contágio era também atribuído ao "ar corrompido" respirado pelos homens. Este "ar" alterava o corpo, putrefazendo-o. Os banhos em águas "fétidas" implicavam macular o corpo para se impor a toda uma série de moléstias. 0 interessante é que, ainda assim, "o banho era prejudicial se tomado em excesso" - "banhar-se em excesso" era fazêlo mais de três vezes por ano ele dilatava os poros do corpo, aumentando a possibilidade de "contato com os miasmas"

A doença também estava associada à abertura para as sensações. 0 homem mais sensível, sensual ou ávido pelas sensações do corpo, i.e, aquele que não se isolava pelo medo da enfermidade, se tornava mais vulnerável ao contágio.

O contato com o "ar corrompido" deveria ser evitado. Assim, as práticas para combater a doença se resumiam basicamente às medidas de isolamento, que protegiam o corpo de influências nocivas à saúde, tais como beber e comer em exagero e ter freqüentes relacionamentos com mulheres 5 .

As práticas contra a doença consistiam na desinfecção do "ar" e das pessoas, ou seja, em acender fogueiras nas encruzilhadas da cidade, passar perfumes e enxofre nos corpos, nos objetos, nas roupas e nas casas, a fim de purificar tudo aquilo que pudesse estar contaminado. $M$ ais raramente, eram aplicados alguns tratamentos fundamentados no conhecimento rudimentar da "cura pelo semelhante". Para evitar marcas, envolvia-se o doente de varíola em um pano vermeIho, mantendo-o deitado em uma cama com cortinas também vermelhas. Acreditava-se que os banhos em águas fétidas protegiam o corpo contra os miasmas. Os picadinhos de serpentes eram ingeridos na forma de poções, com o intuito de proteger os enfermos do veneno da peste. Tam- 
bém havia uma curiosa crença de que os zeladores de latrinas estavam imunizados, o que levava muitas pessoas a visitarem esses estabelecimentos públicos, supondo eficazes seus maus odores$^{3}$. As diversas idéias e prenoções associadas à doença se organizavam na mente humana e davam forma às suas representações que, por sua vez, criavam novos conceitos, teorias e práticas.

Os sinais da doença causavam pavor ao enfermo e aos mais próximos a ele. Os bubões purgavam pus e sangue, sendo acompanhados por manchas escuras resultantes de hemorragias internas. Os doentes sentiam dores muito fortes e geralmente morriam em até cinco dias após a manifestação dos primeiros sintomas. No caso dos pulmões, o doente tinha febre alta e constante, tosse forte, suores abundantes e escarro sangrento, e morriam em três dias ou menos. Em ambos os casos, tudo que saía do corpo hálito, suor, sangue dos bubões e pulmões, urina sanguinolenta e excrementos enegrecidos pelo sangue - cheirava extremamente mal. A depressão e o desespero acompanhavam os sintomas físicos, o que levou alguns escrivães da época a dizer que "a morte se estampava no rosto dos condenados". As pessoas dormiam com saúde e morriam antes de acordar. Foi grande o número demédicose de pessoas caridosas, entreelas freiras, que morreram ao tentar ajudar os doentes ${ }^{3}$. O contágio fulminante ficou bem caracterizado, já que uma pessoa enferma era capaz de "contaminar o mundo".

0 fantasma da peste rondava a vida das pessoas. O bter água limpa para beber e cozinhar era um problema, pois o conteúdo das fossas infiltrava-se no solo e contaminava os poços. Lixo, resíduos de curtume e matadouros poluíam os rios. No interior das casas, a transformação do corpo do doente tornava-se visível com a proximidadeda morte. No ambiente externo, as águas estavam impregnadas dos resíduos eliminados pelos doentes e oriundos dos seus cadáveres em decomposição.

Este cenário afirmava, mais uma vez, a "concepção dos miasmas", que se propagavam pelo ar, transfigurando o corpo humano em restos repugnantes. No caos, entre a vida e a morte, o homem junto com a "peste" também sofria transformações. A "peste", quando não matava, "purificava" o homem. 0 enfermo que conseguia alcançar a cura mudava sua visão sobre o mundo. Ele deixava de temer a doença, pois se sentia capaz devencêla.

A doença, percebida como algo "divino" eestando em um plano superior ao humano ou "profano" tornava-se algo não pal pável, coisa do destino e, assim, fugia ao domínio do homem. As vítimas da peste, consideradas como pecadoras, deviam ser condenadas ao sofrimento. As medidas contra a peste, que eram fundamentadas em princípios morais, censuravam os prazeres sexuais e gustativos do corpo, ainda permanecendo, durante alguns séculos, associados ao pecado, ao profano e ao indigno do divino. A concepção dos miasmas, como meio de contágio das enfermidades, estando relacionada aos fenômenos da natureza - as estações do ano, o clima quente ou frio, os ventos, as tempestades - permanecia passível a mudanças naturais.

$\mathrm{Na}$ antiguidade, Hipócrates (460 a.C. - 380 d.C.), médico grego considerado "pai da medicina", já inaugurava a ciência baseada na observação clínica. Ele considerava como causa das doenças o desequilíbrio entre o que chamava de humores: o sangue, a fleuma (estado de espírito), a bílis amarela e a bílis negra. Para Hipócrates, todo corpo trazia em si os elementos para sua recuperação. M as, o conhecimento do corpo só seria possível a partir do conhecimento do homem como um todo. Assim, o homem representava o microcosmo e o universo, o macrocosmo. 0 microcosmo deveria se encontrar em harmonia com o macrocosmo, ou seja, o corpo humano deveria estar equilibrado com seu ambiente externo. No seu estudo “Ares, Águas e Lugares", ele expõe as influências do ambiente na saúde do homem, ressaltando como fatores essenciais para uma vida saudável, a água isenta de impurezas e 0 ar puro ${ }^{6}$.

A té o século XIX, duas formas polares de representação da doença fundamentaram o saber médico sobre as epidemias: a concepção ontológica, presente no imaginário de praticamente todas as culturas desde a Antiguidade, e a concepção dinâmica, formada no mundo grego, em conformidade com a Physis. Segundo Diniz ${ }^{4}$, as noções de contágio e miasmas estiveram associadas a essas duas concepções de doença. A primeira compreendia a enfermidade como uma entidade concreta que vinha do exterior, tanto do ar como de outros indivíduos e objetos e que não fazia parte da natureza humana. Era uma espécie de mal que invadia o corpo, como espíritos, possessões demoníacas ou flechas lançadas por deuses. $N$ este caso, o homem doente seria aquele ao qual havia se agregado um ser (a doença). A cura seria, em oposição, um esforço para expulsar, por meio de tratamentos mágicos, esse ser estranho.

Já na concepção dinâmica, baseada nas teorias de Hipócrates, a doença surgia em conse- 
qüência do desequilíbrio ou da desarmonia entre o homem e a natureza. Logo, a doença pertenceria ao corpo do homem econstituiria o meio dele readquirir sua harmonia com a natureza, i.e, ela seria uma reação natural e generalizada do organismo, que surgia para recuperar o equilíbrio do corpo.

Entretanto, estas duas concepções convergiam para uma dimensão naturalística, ou seja, a natureza como harmonia e equilíbrio estático (concepção ontológica) ou dinâmico (concepção dinâmica) ea ação interventora da medicina era essencialmente passiva, contemplativa e consistia em apenas potencializar as tendências naturais. Segundo compreendia a medicina hipocrática-galênica, a simples absorção do ar corrupto degenerava os humores corporais que, ao serem expelidos pelos poros ou pela respiração, poderiam corromper 0 ar. A noção do contágio envolvia não só aquilo que poderia decorrer do contato, mas também da simples aproximação. Não havia como distinguir, com clareza, contágio e miasmas.

Contudo, ainda no século XVI, Fracastoro (1478 - 1553), em suas observações sobre a natureza e a disseminação das doenças infecciosas, supôs que as infecções passavam de uma pessoa a outra por meio de pequenos corpos capazes de auto-reprodução. Ele definia o contágio como uma corrupção ou infecção, que ocorria de forma anál oga entre portadores e receptores, ocasionada por partículas imperceptíveis ${ }^{4}$.

Nos dias de hoje, reconhecemos a peste como uma doença de cadeia epidemiológi ca complexa, envolvendo roedores, carnívoros domésticos (cães e gatos) e silvestres (pequenos marsupiais), pulgas e o homem. É uma doença infecciosa e contagiosa, possuindo como agente etiológico a bactéria Yersinia pestis, que é transmitida ao homem pela picada da pulga infectada, encontrada principalmente nos ratos. As gotículas transportadas pelo ar e as secreções bronquiais de pacientes com peste pneumônica constituem os meios de transmissão mais freqüentes de pessoa a pessoa. Tecidos de animais infectados, fezes de pulgas e culturas de laboratórios também são fontes de contaminação para quem os manipula sem obedecer a normas de biossegurança. A sua persistência em focos naturais, no Brasil e em outros países do mundo, é uma importante característica ecológica e epidemiológica da doença, dificultando a sua erradicação e impondo a manutenção da sua vigilância e controle, mesmo quando em baixas incidências ${ }^{7}$.

A partir do século XX, a epidemiologia come çou a ser prejudicada pela visão monocausal das doenças, i.e, o combate a determinada epidemia tornou-se restrito à eliminação do agente etiológico ede seus vetores. A análise epidêmica deuma doença não deve ficar limitada ao seu aspecto objetivo, ou seja, ao entendimento do seu ciclo de transmissão: o agente etiológico, os vetores, os reservatórios e as condições ambientais, em queela se desenvolve. Além disso, também precisamos conhecer a subjetividade daqueles que se contaminaram - os traços singulares físicos e psíquicos das pessoas infectadas; em quecircunstâncias elas se contaminaram; quais são suas condições de vida e suas raízes culturais e, ainda, como elas percebem a doença no seu corpo.

Situação semelhante pode ser observada no caso dos resíduos que, até a década de 1950, foram associados a doenças, permanecendo restritos à área médica. O lixo eos seus riscos somente a partir da década de 1970 começaram a ser considerados como questão ambiental. Foi quando percebemos quanto o nosso planeta estava sendo degradado pelos resíduos gerados por substâncias de origem biológica, química e radioativa, que vinham deteriorando a saúde do homem e do seu ambiente. Estas substâncias foram produzidas pelo próprio homem e, algumas vezes, apesar de descoberta a sua toxicidade e, em certos casos, a sua letalidade, as autoridades continuaram sendo negligentes quanto à destinação final detais substâncias. 0 homem cria situações em que, apesar de conhecer os perigos, prefere arriscar-se. N esse aspecto, o que está sendo priorizado - a integridade das medidas de saúde pública ou o "poder" econômico da sociedade de consumo globalizada?

\section{O lixo como estigma social}

Conforme os acontecimentos ocorridos no século XIV, no que se refere à epidemia da peste negra, pudemos observar as diferentes formas de representações dos fatos, relacionadas a possíveis causas da enfermidadee seu contágio. Contudo, ainda hoje, os resíduos são vistos como algo ameaçador e são geralmente enviados para locais bem distantes dos nossos espaços físicos de convívio e para longe, também, dos nossos pensamentos.

Os resíduos reconhecidos como restos, lixo ou como tudo aquilo desprovido de uma utilidade óbvia e, portanto, objetiva, foram adquirindo uma imagem negativa, quase sempre associada à sujeira, à doença, à morte e à miséria. 
No final da I dade M édia e na M odernidade, as pessoas que cuidavam do destino final do lixo eram marginais à sociedade. Assim como o resto ou a sobra, esses seres humanos também eram escolhidos de acordo com a ocupação ou com o papel social que desempenhavam. N este período, os serviços de limpeza estiveram freqüentemente subordinados ao carrasco da cidade e eram executados pelos seus auxiliares. As tarefas ligadas aos restos, inclusive o destino de cadáveres, eram delegadas a prostitutas, prisioneiros de guerra, condenados, escravos, ajudantes de carrascos e mendigos. Tal fato é importante para a compreensão de como o trabalho com resíduos foi sendo socialmente desqualificado. Segundo $\mathrm{Hösel}^{8}$, na cidade de Berlim na Alemanha, começou-se a empregar prostitutas na limpeza das ruas, usando-se como argumentação o fato de que elas"usavam mais as ruas do que os outros cidadãos" 8 .

Durante o período medieval, o lixo era basicamente originado pela necessidade fisiológica, pela alimentação e pelo vestuário do homem. Já existiam os catadores de lixo, que eram chamados de trapeiros. Segundo Portilho ${ }^{9}$, desde aque la época até os dias atuais, as pessoas que trabaIham ou vivem do lixo - catadores, coletores eaté mesmo os engenheiros sanitaristas - são estigmatizados pela sociedade. São vistos, da mesma maneira, os espaços destinados ao tratamento e ao destino final dos resíduos - lixões, vazadouros, depósitos, aterros sanitários, usinas de reciclagem e estações de tratamento de esgotos.

Ainda hoje, a exclusão dos catadores de lixo é tão perversa, que chega à criminalidade. Por sobreviverem daquilo que é descartado, estes seres humanos são desconhecidos como cidadãos e identificados como "descartáveis". Rodríguez ${ }^{10}$ comenta o fato ocorrido no ano de 1992, na cidade de Barranquilla, na Colômbia, quando onze "descartáveis" foram assassinados e seus corpos utilizados para experiências médicas em um centro universitário. 0 crime deu origem à rede de cooperativas de recicladores da América Latina, que foram criadas no intuito de valorizar a ocupação e de reconhecer os "descartáveis" como profissionais "recicladores de resíduos".

No estudo realizado por Velloso ${ }^{11}$ com os coletores de lixo da Companhia Municipal de Limpeza U rbana no Rio dejaneiro (COM LURB), também podemos perceber a presença de uma hierarquia perversa entre os profissionais. Durante esse estudo, a pesquisadora acompanhou o processo de trabalho daqueles profissionais, viajando na boléia do veículo coletor. $\mathrm{Na}$ ocasião, conversando nos bares com os motoristas e coletores, enquanto descansavam do serviço, ela pode entender a posição de inferioridade que o coletor sentia em relação ao motorista. 0 coletor viajava no estribo do veículo, ficando vulnerável ao movimento do trânsito, expondo-se inclusive a quedas. 0 trabalhador, mesmo enfrentando fortes chuvas, altas ou baixas temperaturas, não viajava na boléia, pois, na lida direta com o lixo, ele se sentia inferior ao motorista. [...] a cabine é para o motorista, porque tem diferença do motorista para o gari, tem a discriminação e muitos deles se acham donos daquela cabine. Quando está sol ou quando está chovendo, o gari vai atrás do caminhão para evitar conflito com 0 motorista, mesmo que ele ofereça, a gente não vai, porque nós estamos sujos e ele, por estar limpinho, acha que não devíamos estar ali $[. . .]^{11}$.

0 coletor fala sobre os riscos presentes no processo da coleta do lixo, dos acidentes sofridos, das doenças e das condições inóspitas do ambiente de trabalho. Contudo, o menosprezo da população e da empresa, pelo seu serviço, parece a principal causa da sua insatisfação: [...] eles discriminam, eles olham para o gari como olham um porco. Eles não sabem que o gari é um homem ou uma mulher igual a eles. As pessoas têm nojo da gente, acham que a gente tem uma doença contagiosa. A gente entra no ônibus as pessoas se afastam da gente $[. . .]^{11}$.

Estes profissionais não gostam de ser chamados de "lixeiros", preferem ser identificados como "garis". Mas nem sequer conheciam a origem desta denominação, que vem do início do século $X X$, quando os serviços de limpeza urbana foram entregues à iniciativa privada e os irmãos Garys assumiram a Companhia Industrial do Rio de Janeiro, com o objetivo de desempenhar os serviços de coleta, transporte e destino final do lixo. Desde então, os trabalhadores da coleta do lixo passaram a ser chamados pelo nome genérico dos seus patrões, "garis"11.

A nomeação não éum ato registrado em cartório, mas um sinal de pertença social. A inserção é uma criação contínua do sujeito, ou seja, ela é dada por um nome e por uma dignidade, conferidos por um trabalho que não se limita ao aspecto de uma mecânicajá preestabelecida, mas, sim, de uma mecânica criada.

0 fato de o coletor de lixo preferir ser reconhecido pelo nomedos seus patrões interage com a imagem negativa que a população formou sobre ele e denuncia o seu desprezo pela própria profissão, que não Ihe confere a pertença social. 0 uniforme, que é obrigado a vestir, o torna invisível aos seus "superiores", mas também o faz 
ser reconhecido como trabalhador, ou seja, ele passa a não ser um marginal à sociedade. No entanto, elenão évisto como uma pessoa e, sim, como um "lixeiro"', que apenas cumpre sua função social.

A experiência do psicólogo social Fernando Braga da Costa comprova a invisibilidade que é atribuída à profissão de coletor do lixo. Ele fingiu-se de gari evarreu as ruas da Universidade de São Paulo (USP), a fim de concluir sua dissertação de mestrado sobre invisibilidade pública, ou seja, a tese abordava a percepção humana, quando total mente prejudicada e condicionada à divisão social do trabalho, quefaz com que se enxergue apenas a função e não a pessoa. Fernando, usando o próprio corpo, ao vestir o uniforme, tinha a intenção de sentir-se como um gari. Ele trabal hava meio expediente e não recebia, como os seus "colegas de vassoura", o salário de quatrocentos reais. N esta condição, garante que teve a maior lição da sua vida: “D escobri que um simples bom dia, que nunca recebi como gari, pode significar um sopro de vida, um sinal da própria existência". O psicólogo sentiu, na [própria] pele, o que é ser tratado como um objeto e não como um ser humano: professores que me abraçavam nos corredores da USP passavam por mim enão me reconheciam, por causa do uniforme. Às vezes, esbarravam no meu ombro e, sem ao menos sedesculparem, seguiam me ignorando, como se estivessem encostado em um poste, ou em um orelhão. Apesar do sol forte, do trabalho pesado e das humilhações diárias, Fernando constatou que os garis são acolhedorescom quem os enxergam eencontram; no silêncio, a defesa contra quem os ignora ${ }^{12}$.

A valorização do lixo começa a surgir no período industrial eamplia-se por causa da guerra. O lixo deveria ser transformado em dinheiro. Numa sociedade capitalista, geralmentesó seatribui valor a coisas que podem gerar lucro. Este valor foi atribuído ao lixo, devido à possibilidade de sua transformação em matéria-prima. Assim, em 1896, os trapeiros iniciam suas atividades, intensificando-as a partir de 1918. Existiam dois tipos de trapeiros: 0 catador e 0 atacadista. 0 primeiro fazia a separação dos materiais encontrados no lixo e os enfardava para serem vendidos como matéria-prima. Ele era o "operário", enquanto que 0 atacadista - 0 "atravessador" era o patrão. H avia uma tensão entre as indústrias de trapos e o Serviço Sanitário, apesar delas terem sido toleradas até o término da Primeira Guerra M undial. Em várias situações, os trapos eram importados, sobretudo da Argentina e, mais tarde, da Europa. 0 Serviço Sanitário co- meçou a exigir a desinfecção dos fardos, queapresentavam um "aspecto repugnante". Esta medida foi dificultando a importação de trapose, conseqüentemente, a sua comercialização ${ }^{13}$.

Assim, o interesse econômico em manter a indústria de trapos, foi "vencido" pelas medidas dehigieneexigidas pelo Serviço Sanitário. A partir de 1914, seguindo o relato de M iziara ${ }^{13}$, a Prefeitura de São Paulo foi encarregada de criar um estatuto para o lixo, no qual, além da higiene, estavam em questão a moral e a civilidade. N esse sentido, "o estado sanitário do trapeiro" transformou-se em grande preocupação para a saúde pública. 0 maior índice de doenças contagiosas era transmitido pelos trapeiros, uma vez que "não lavavam as mãos para comer". A higiene foi compreendida como um "método estratégico de excluir a população da ocupação de utilização do lixo". Por fim, o Serviço Sanitário propõe à cidade que adote novas carroças e quatro fornos de incineração com capacidade para incinerar cinqüenta toneladas de lixo por dia, sendo distribuídos pelos bairros do Brás, Luz, Barra Funda e Liberdade. Cabe ressaltar que, com a instalação dos quatro fornos em São Paulo, poderiam ser queimadas duzentas toneladas de lixo/dia, apesar dea cidade produzir, no período, cento evinte toneladas diárias. Seria necessária a produção de mais lixo para justificar a aquisição dos equipamentos.

Cabe lembrar que, no século XX, na década de 1970, houve retorno à prática de reaproveitar o "lixo", que se manifestou na moda de se usar roupas vel has e desbotadas - a calça Lee e o "casaco de general". O modismo, na época, representou uma forma de se contestar o sistema repressor da ditadura militar que, muitas vezes, marcou de forma irreparável milhares de jovens e adultos que atuaram politicamente contra as arbitrariedades do governo. Esta transformação na moda, por sua vez, a partir dos anos 1960, emergiu com o movimento hippie e de estudantes, que buscavam a afirmação dos seus desejose direitos proibidos.

A tensão entre o valor de mercado e o valor humano permanece, induzindo as diferentes visões sobre o lixo, que variam de acordo com os interesses econômicos - ora o lixo é visto como risco de vida, transmitindo doenças e causando mortes, ora é considerado como matéria-prima, produzindo elançando novos produtos no mercado.

Atualmente, a visão do lixo como matériaprima já está incorporada no discurso do coletor de lixo. Fato percebido quando ele se refere à companhia de limpeza urbana, para a qual tra- 
balha, como sendo rica em matéria-prima: [...] 0 lixo é muito rico, a COM LURB éuma companhia que nunca vai entrar na falência, entra se os outros quiserem. Porque o lixo nunca acaba e a matéria-prima dela é o lixo. Ainda mais agora, com essas usinas que eles criaram equeestão reciclando direto $[\ldots]^{11}$.

A sociedade deconsumo aposta na vida breve dos seus produtos. Ela fabrica produtos que devem ser rapidamente substituídos por outros, cada vez mais frágeis e perecíveis. Enquanto isso, nossos resíduos saturam os depósitos e as usinas dereciclagem. Jánão há espaço físico para depositar ou reciclar os restos resultantes da quantidade de produtos que produzimos e descartamos.

\section{As medidas de higi ene e a saúde pública}

O século XVII foi o palco do Renascimento, um dos maiores movimentos culturais da história da humanidade, que representou uma época de enriquecimento do pensamento, aliado a uma transformação profunda da atitude espiritual do homem. A ânsia da descoberta e a paixão pelo mundo clássico puseram à disposição do homem culto as doutrinas dos filósofos gregos e orientais. Todo o século consistiu em um período de transição, no qual o homem ocidental impulsionou a ciência, fundamentada nos novos conhecimentos da física, da astronomia e das ciências naturais. 0 Renascimento conteve em si o germe da destruição, mas também a promessa da renovação. A religiosidade e a política da Europa foram fortemente abaladas e o mundo transfigurou-se. 0 homem redescobreem si o potencial criador, mas, em vez de criar em harmonia com a natureza, julga-seseparado edistinto dela, sentimento que não só persistiu como foi ampliado com o passar dos séculos. As viagens marítimas, iniciadas pelos portugueses, propiciaram aos europeus 0 impulso transformador da visão clássica em uma nova perspectiva demundo. No domínio da medicina, o Renascimento representou, de um lado, um retorno às raízes, ou seja, à ciência deH ipócratese, de outro lado, o interesse pela observação e pela experiência ${ }^{14}$.

As experiências científicas foram evoluindo e gerando novas descobertas. O século XVII foi marcado pelos avanços da medicina, i.e, pelos conhecimentos acadêmicos, que descobriram a circulação do sangue, a química da respiração e, através do aperfeiçoamento do microscópio simples, os agentes microbianos causadores de algumas doenças. Assim, Redi, que era médico ebió- logo de Florença, realizou as primeiras descobertas que deram origem à teoria da biogênese. Em seguida, Leewenhoek, aperfeiçoando o microscópio, descobriu as bactérias. A penas por volta de 1880 , com as experiências de Pasteur, a teoria da geração espontânea é posta de lado ${ }^{15}$.

Estas descobertas contribuíram para uma outra visão de cidade, propiciando novas concepções de sujeira corporal e urbana. As cidades começam a ser planejadas, inspiradas na circulação do sangue e nos movimentos da respiração. Elas deviam ser amplas para que 0 ar circulasse livremente, sendo divididas em ruas principaise secundárias, da mesma forma que as veias e artérias do corpo humano, que transportam hemácias e outros elementos do sangue para os órgãos. Os resíduos, como fezes e urina, deveriam sair das casas através de um cano parcial, que nas ruas se acoplariam a um cano comum ou principal (rede de esgoto).

Contudo, na primeira década do século XIX, as ruas de algumas cidades ainda apresentavam sujeiras provenientes de resíduos domésticos. Nesse período, a cidade de Lisboa é descrita por Braga ${ }^{16}$ como detentora de espaços naturalmente contaminados pelos despejos da famosa água "vai", do lixo doméstico e dos animais que passeavam pelas ruas, nomeadamente cães vadios, vacas, cabrase outros animais utilizadosno transporte, tais como cavalos, burros e bois. A situação era agravada pela passagem de rebanhos de carnei ros e varas de porcos com destino a outras regiões; pela construção de fábricas poluentes e matadouros dentro das cidades e pela ausência de calçamentos nas ruas.

Para contornar a caótica falta de higiene na cidade, em $1^{\circ}$ de abril de 1818, foi lançado um edital onde constavam al gumas medidas de higiene a serem seguidas. Entre elas, foi proibido se despejar dejetos e lixos nas ruas de Lisboa, estabelecendo multas para os infratores, as quais variavam de acordo com a gravidade e o horário do delito. 0 lixo deveria ser acondicionado em recipientee colocado na rua, depois das 22 horas, para ser recolhido pelos carros de limpeza ${ }^{16}$.

Em 1835, segundo o relato da autora, iniciouse um plano que articulava a higiene com a saúde dos habitantes de Lisboa. Este plano evidenciava, entre outros aspectos, a necessidade de dividir a cidade em dez zonas, cada uma delas doadora de homens e carros de bois destinados à limpeza da cidade eque, em contrapartida, se encarregariam do fornecimento gratuito de estrume de boi aos trinta e três agricultores. Era responsabilidade destes homens: a eliminação de cães vadios; fazer 
cumprir a proibição de ensinar as bestas novas e de matar porcos nas vias públicas; a varrição das ruas, três vezes por semana e, por fim, a recolha diária dos detritos. 0 plano estabelecia, ainda, que os senhorios deveriam construir cloacas fora de suas casas, nas ruas, com canos gerais. $N$ as cozinhas de todos os andares das casas, deveriam ser instaladas pias com ralos, destinadas ao despejo delíquidos. Os senhorios deveriam, também, encanar as águas dos tel hados e caiar a fachada dos prédios, de três em três anos, de preferência na cor rosa desvanecido.

Neste período, já verificamos uma hierarquização de objetos, que devem seguir uma norma de organização. Assim, o lixo permanece estocado, com a intenção de ser transformado. Os resíduos, como os estrumes de bois, são encaminhados aos agricultores, para serem reutilizados como adubos. Os resíduos do corpo humano, fezes e urina, devem seguir normas no seu destino final. As ruas devem permanecer limpas, sem resíduos e animais, que são identificados como riscos à saúde e ao bem-estar da população. Também surge a preocupação com a estética dos prédios, que foram pintados de rosa pálido, buscando-se na uniformização da cor, a harmonia, a limpeza e a beleza da cidade.

Quanto à higiene pessoal ou individual, os banhos eram escassos e de difícil acesso. As pessoas trocavam de roupas raramente, quando essas já se encontravam muito sujas. Para alguns, a higiene pessoal se restringia à troca de roupas, sem submeterem-se a qualquer ablução. Como a maioria dos lares não possuía casas de banho, a higiene individual ficava a mercê dos hábitos e dos conceitos de limpeza de cada um, bem como do número de criados que se incumbia de carregar a água. Contudo, as idas às termas ou aos banhos de mar erio começaram a tornar-secada vez mais freqüentes. A partir do século XVIII, verificou-se um crescimento da população de Caldas da Rainha, associado à grande concorrência termal. Segundo os estudos realizados por $\mathrm{Braga}^{16}$, essas termas eram freqüentadas pelos nobres da cidade e ficavam muito aquém das suas similares européias, no que dizia respeito ao local das nascentes e das fontes: [...] era um lugar imundo, o cheiro era terrível e o pouco asseio que ali havia tornava aquele lugar repugnante evergonhoso para nós, na presença de vários estrangeiros que faziam a triste comparação dos nossos banhos termais com outros que tinham visitado na Europa civilizada. Os banhos tomavam-se em comum, havendo só dois, um para cada sexo[... $]^{16}$.

No plano da arte, a criação de novas formas fora da modelagem habitual começa a surgir. Em Portugal, não havia os recursos financeiros de países como a I tália e a França, mas eles ostentavam o modelo desses países, no que se referia às estações termais. Por isso, elas eram desvalorizadas e vistas como inferiores às suas similares européias.

$\mathrm{Na}$ segunda metade do século XIX, com a emergência da teoria microbiana das doenças, que refutou a concepção dos miasmas, houve uma radical mudança na visão da saúde pública e da atenção a ser dada aos resíduos eliminados pelo corpo humano. Segundo Eigenheer ${ }^{8}$, as tradicionais concepções de tratamento do lixo passam por visíveis transformações. N este contexto, a fogueira, anteriormenteutilizada para purificar o ar, torna-se a fonte inspiradora do incinerador (construído na Inglaterra, em 1875), que começa a ser considerado como o método ideal para eliminar os agentes microbianos, transmissores das doenças infecciosas. Os trapeiros, mestres na arte da recolha e separação dos restos, vão gerar o modelo das usinas de reciclagem em Bucarest (1895) e em Munchen (1898).

Neste mesmo período, no Brasil, durante o governo Campos Salles (1898-1902), foi criado o Instituto de $M$ anguinhos, com a função de fabricar vacinas contra a peste bubônica. Para dirigi-lo, a prefeitura da capital federal solicitou ao Instituto Pasteur, de Paris, para indicar um especialista. Naturalmente esperava-se um francês, mas o célebre Emile Roux, diretor do Instituto, indicou um "brilhante discípulo", Oswaldo Gonçalves Cruz (1872-1917) que, mesmo sem alcançar os trinta anos e desconhecido no Brasil, já conquistara uma sólida reputação científica. Ele dirigiu M anguinhos até 1902, quando Rodrigues Alves, ao assumir a Presidência da República, foi buscá-lo para sanear o Rio de Janeiro. Ao aceitar o convite, Oswaldo cruz prometeu erradicar a febre amarela, num período de três anos. Mas, primeiro, começou resolvendo o problema da peste. Para combatêla, formou um esquadrão de cinqüenta homens, todos previamente vacinados, que percorriam os armazéns, becos, cortiços e hospedarias, espal hando raticida e removendo o lixo. Para completar, criou um novo cargo - o de comprador de ratos. Este funcionário percorria as ruas da cidade, do centro aos subúrbios, pagando a quantia detrezentos réis por cada rato caçado pela população. Assim, num curto prazo, desapareceram as epidemias e os ratos. $\mathrm{N}$ a verdade, a eliminação dos ratos e da peste insere-se num contexto de transformações que envolveram a capital do Brasil, no início do sécu- 
lo XX - com a afirmação da teoria microbiana, as medidas de higiene começaram a ser aplicadas no combate aos vetores e aos agentes etiológicos das doenças infecciosas ${ }^{17}$.

0 combate à febre amarela apresentou vários problemas. A maior parte dos médicos e da população ainda acreditava que a doença era transmitida pelo contato com as roupas e as secreções dos doentes. Oswaldo Cruz, entretanto, era adepto da teoria dequeo agenteetiológico da doença era transmitido pelo mosquito. Assim, ele decidiu substituir o método tradicional das desinfecções praticadas pela polícia sanitária, pelas brigadas de mata-mosquitos. Essas brigadas percorriam ruas, invadindo casas para eliminar os focos de insetos, atuação que provocou violenta reação popular ${ }^{18}$.

Em 1904, com o agravamento dos surtos de varíola, o sanitarista tentou impor a vacinação em massa da população. M as os jornais lançaram intensa propaganda contra a medida. 0 Congresso protestou e foi organizada uma liga contra a vacinação obrigatória. No dia 13 de novembro, estourou a rebelião popular. 0 governo derrotou a rebelião, mas suspendeu a obrigatoriedade da vacina.

Este episódio da história nos remete ao autoritarismo das medidas de erradicação das doenças, impostas à população no início do século $X X$. Tais medidas, por não terem sido acompanhadas do reconhecimento da população, foram percebidas como atos de violência e de imposição. A ansiedade do jovem Oswaldo Cruz em erradicar as doenças não o deixou perceber a necessidade de se trabalhar junto à população, na produção do conhecimento sobre as doenças infecciosas e os seus meios de transmissão.

Os riscos associados aos resíduos foram considerados durante muitas décadas como questão de higiene pública e, portanto, limitados à área médica. Ainda nos anos cinqüenta, encontramos capítulos destinados ao lixo quase que exclusivamente em tratados de higiene, sempre extremamente reduzidos quando comparados a outros temas de saneamento, como água e esgoto ${ }^{8}$.

Somente a partir da década de 1970, o lixo começa a ser considerado uma questão ambiental. A preservação do meio ambiente foi assumindo caráter global, com as conferências de Estocolmo, em 1972, a ECO 92, no Rio deJaneiro ea de Tibilisi, em 1997. A crescente participação da mídia também contribuiu significativamente para esse processo, devido à rapidez com que as informações são transmitidas, de um lugar a outro do mundo. 0 crescimento progressivo das indústrias e conseqüentemente o lançamento de novos produtos no mercado foram gerando diversos e perigosos resíduos. Atualmente, já se compreende que as agressões ambientais que ocorrem em determinado ponto do planeta podem ter repercussão à distância, atingindo mesmo outros continentes, como por exemplo, os casos de acidentes radioativos, as chuvas ácidas e os derramamentos de petróleo nos mares.

\section{Consideraçõesfinais}

A visão dos resíduos, como veículos de enfermidade, permaneceu durante al guns séculose, atualmente, ainda podemos perceber os resquícios dessa visão na gestão dos Resíduos dos Serviços de Saúde (RSS). A classificação de cada resíduo segundo sua origem - hospitalar, domiciliar, industrial e de logradouros públicos - dá início aos diferentes processos de organização. As etapas referentes ao acondicionamento, ao transporteeao destino final devem ser específicas para cada tipo de resíduo. 0 homem, na sua ânsia de produzir soluções, muitas vezes ten deà generalização, reduzindo as medidas de contenção a um dos seus aspectos, como é o caso das normas estabelecidas para o lixo hospitalar ou RSS, que recomenda a esterilização de todos os resíduos, sem exceção. Estes resíduos, com algumas exceções, não necessitam passar por tratamentos especiais, podendo ser tratados como lixo comum $^{19}$. A controvérsia existente sobreo tema, de que todos eles, sem exceção, devam passar pelo processo de incineração ou de desinfecção, pode estar vinculada aos temores do passado, quando os microorganismos transmissores de doenças tinham sua origem desconhecida e causavam, normalmente, a morte do enfermo.

Nos dias de hoje, apesar dos resquícios destas recordações do passado, o lixo mais temido é aquele produzido pelo homem, que é capaz de destruir, em escala planetária, a vida humana ea natureza. A contaminação ambiental pelas radiações nucleares, pelas substâncias químicas, pelos agentes biológicos, bem como os atos mecânicos de violência entre os homens, têm destruído milhares de vidas.

A matéria intitulada "Aterro lixo pode tornar-se um cemitério" narra o indelével fim das vítimas do atentado terrorista ocorrido em 11/ 09/2001, na cidade de Nova I orque, quando os terroristas usaram o próprio corpo - os "homens bomba" - como arma de destruição, sacrificando suas próprias vidas. No final, o país que 
sempretevesua economia fundamentada no consumo de produtos transformou um depósito de lixo em cemitério, ou melhor, os restos resultantes do atentado terrorista foram levados ao antigo aterro sanitário, que havia sido desativado a pedido dos moradores locais. Assim, restos de corpos humanos, sobras de concreto, pedaços de aeronaves e diversos materiais de consumo foram transportados como lixo e descartados no mesmo depósito ${ }^{20}$.

A bem da verdade, o homem, ao criar determinado produto, muitas vezes desconhece seus possíveis efeitos tóxicos e letais. No entanto, esse produto faz com que a classe hegemônica de vários países se sinta "poderosa", quando, por exemplo, possui o controle de uma arma destrutiva eameaçadora. Cabe lembrar o caso do físico Bronowski, membro da equipe do Projeto $\mathrm{Ma}$ nhattan, que produziu a bomba atômica, tragicamente utilizada na Segunda Guerra M undial. Bronowski, na década de 1970, confessou seu desconhecimento edescontentamento pelo fato dos seus estudos de física atômica contribuírem para a fabricação de uma arma de capacidade letal ainda não superada, a ser usada contra o próprio homem.

O descuido e a ignorância relacionados ao destino final de produtos que causam riscos à população e ao ambiente são claramente evidenciados no caso da contaminação pelo césio 137, ocorrido na cidade de Goiânia, no Brasil. Um aparel ho de césio-137, que se encontrava fora do seu uso em tratamentos médicos, foi descartado num gal pão. Dois sucatei ros encontraram o aparelho e, não sabendo a sua função e risco, foram seduzidos pelo brilho de um pó branco. Passaram-no pelo corpo como se fosse uma purpurina, disseminando aquela coisa mortífera pela cidade ${ }^{21}$. A negligência no descarte do lixo radioativo por parte das autoridades responsáveis e a ignorância da população sobre a sua periculosidade conduziram à contaminação radioativa, causando danos de repercussão mundial. 0 acidente, além da terrível tragédia humana, foi também um desastre para a economia de Goiânia ninguém queria viajar para a cidade e os seus produtos passaram a ser evitados. Este acidente mostra que, além da irresponsabilidade no descarte de resíduos radioativos, também existe 0 despreparo em lidar com as tecnologias dos países de economia central - compramos tecnologia do primeiro mundo, mas não seguimos as normas de contenção que deveriam ser aplicadas a essa tecnologia.

\section{Agradecimentos}

A Jorge de Campos Valadares, meu orientador, pela contribuição valiosa para elaboração do capítulo da tese, que originou o presente artigo. A Carlos Molinaro, doutorando da Universidade Pablo OlavidedeSevilha, quemeajudou na compreensão do latim, necessário à leitura das obras do século XVI. 


\section{Referências}

1. Ferreira ABH. Novo Dicionário Aurélio - século XXI Dicionário da língua portuguesa. $3^{a}$ ed. Rio de Janeiro: N ova Fronteira; 2004.

2. Ursino G. Elegia de peste. [Catálogo de obras raras] Coimbra: Biblioteca Geral da Universidade de Coimbra; 1541. [M imeo]

3. Dessennius B. De peste. [Catálogo de obras raras]. Coimbra: Biblioteca Geral da Universidade de Coimbra;1568. [M imeo]

4. Diniz A. S. Epidemia: história epistemológica e cultural. Revista Política \& Trabalho 1999; (15):179-192.

5. Czeresnia D. Do contágio à transmissão: ciência e cultura na gênese do conhecimento epidemiológico. Rio de Janeiro: Fiocruz;1997.

6. Jones WHS. Hipocrates, Airs, Waters, Places. Cambridge: Harvard University Press; 1948.

7. Fundação Nacional de Saúde. [site na Internet]. Vigilância epidemiológica de doenças e agravos específicos; 1999. [acessado 2004 Fev 10]. Disponível em: http://www.funasa.gov.br

8. Eigenheer EM. Lixo e vanitas: considerações de um observador de resíduos [tese]. Niterói(RJ): Universidade Federal Fluminense; 1999.

9. Portilho MFF. Profissionais do Lixo: um estudo sobre as representações sociais de engenheiros, garis e catadores [dissertação]. Rio de Janeiro (RJ): Universidade Federal do Rio de Janeiro;1997.

10. Rodríguez C. À procura de alternativas econômicas em tempos de globalização: o caso das cooperativas de recicladores de lixo na Colômbia In: Santos BS, organizador. Produzir para viver: os caminhos da produção não capitalista. Rio de Janeiro: Civilização Brasileira; 2002

11. Velloso M P. Processo de trabalho da coleta do lixo domiciliar na cidade do Rio de Janeiro: percepção e vivência dos trabalhadores [dissertação]. Rio de Janeiro (RJ): Escola Nacional de Saúde Pública, Fiocruz; 1995.

12. Segala K. Alquém que fingiu ser gari. Web-resol. Instituto para a democratização de informações sobre saneamento básico e meio ambiente. [site na Internet]. [acessado 2004 Fev 16]. Disponível em: http://www.resol.com.br/curiosidades2.asp?id=1227
13. M iziara R. Nos rastros dos restos: as trajetórias do lixo na cidade de São Paulo. São Paulo: EDUC; 2001

14. Rodrigues MH. A medicina no tempo das descobertas e os serviços de Saúde Pública nos territórios ultramarinhos. Africana 1999; 20.

15. Rodrigues MH. A evolução dos serviços de Saúde Pública nas províncias ultramarinhas do século XVIII ao final do século XIX. Africana 1999; 21.

16. Braga MIRMD. Assistência, Saúde Pública e prática médica em Portugal: séculos XV-XIX. Lisboa: Universitária; 2001.

17. Historia net: a nossa historia.Curso de Historia. Brasil República [site na Internet]. Caçando ratos. [acessado 2004 Fev 16]. Disponível em: http://www. historianet.com.br/conteudo/default.aspx?codigo $=367$

18. M ini Web Educação. Instituto Oswaldo Cruz. [site na Internet]. Oswaldo Gonçalves Cruz: biografia. [acessado 2004 Fev 12]. Disponível em: http://www. miniweb.com.br/Cidadania/Personalidades/ oswaldo cruz.html

19. Zanon U. Riscos infecciosos imputados ao lixo hospitalar: realidade epidemiológica ou ficção sanitária? Revista da Sociedade Brasileira de M edicina Tropical 1990; 23(3):163-170.

20. Langton J.Web-resol. [site na Internet] Aterro lixo pode tornar-se um cemitério.This is London. [acessado 2004 Fev 16]. Disponível em: http://www.resol. com.br/curiosidades2. asp?id $=962$

21. Frazão J. Siron Franco: pinturas em série [dissertação]. Rio de Janeiro (RJ): Universidade Federal do Rio de Janeiro; 1998.

Artigo apresentado em 08/02/2006

Aprovado em 01/02/2007

Versão final apresentada em 16/02/2007 